\title{
PRIM1 deficiency causes a distinctive primordial dwarfism syndrome
}

\author{
David A. Parry, ${ }^{1,7}$ Lukas Tamayo-Orrego, ${ }^{1,7}$ Paula Carroll, ${ }^{1}$ Joseph A. Marsh, ${ }^{1}$ Philip Greene, ${ }^{1}$ \\ Olga Murina, ${ }^{1}$ Carolina Uggenti, ${ }^{2}$ Andrea Leitch, ${ }^{1}$ The Scottish Genomes Partnership, ${ }^{8}$ Rita Káposzta, ${ }^{3}$ \\ Gabriella Merö, ${ }^{3}$ Andrea Nagy, ${ }^{3}$ Brigitta Orlik, ${ }^{4}$ Balázs Kovács-Pászthy, ${ }^{3}$ Alan J. Quigley, ${ }^{5}$ \\ Magdolna Riszter, ${ }^{3}$ Julia Rankin, ${ }^{6}$ Martin A.M. Reijns, ${ }^{1}$ Katalin Szakszon, ${ }^{3}$ and Andrew P. Jackson ${ }^{1}$ \\ ${ }^{1}$ MRC Human Genetics Unit, MRC Institute of Genetics and Molecular Medicine, the University of Edinburgh, Edinburgh EH4 \\ 2XU, United Kingdom; ${ }^{2}$ Centre for Genomic and Experimental Medicine, MRC Institute of Genetics and Molecular Medicine, \\ the University of Edinburgh, Edinburgh EH4 2XU, United Kingdom; ${ }^{3}$ Institute of Pediatrics, Faculty of Medicine, University \\ of Debrecen, Debrecen H-4032, Hungary; ${ }^{4}$ Institute of Pathology, Faculty of Medicine, University of Debrecen, Debrecen H-4032, \\ Hungary; ${ }^{5}$ Department of Radiology, Royal Hospital for Sick Children, Edinburgh EH9 1LF, United Kingdom; ${ }^{6}$ Department \\ Clinical Genetics, Royal Devon and Exeter NHS Foundation Trust, Exeter EX1 2ED, United Kingdom
}

DNA replication is fundamental for cell proliferation in all organisms. Nonetheless, components of the replisome have been implicated in human disease, and here we report PRIM1 encoding the catalytic subunit of DNA primase as a novel disease gene. Using a variant classification agnostic approach, biallelic mutations in PRIM1 were identified in five individuals. PRIM1 protein levels were markedly reduced in patient cells, accompanied by replication fork asymmetry, increased interorigin distances, replication stress, and prolonged S-phase duration. Consequently, cell proliferation was markedly impaired, explaining the patients' extreme growth failure. Notably, phenotypic features distinct from those previously reported with DNA polymerase genes were evident, highlighting differing developmental requirements for this core replisome component that warrant future investigation.

[Keywords: DNA replication; genome stability; growth disorders; human genetics; rare disease]

Supplemental material is available for this article.

Received May 9, 2020; revised version accepted September 18, 2020.

Microcephalic primordial dwarfism (MPD) disorders constitute several Mendelian syndromes characterized by intrauterine growth retardation, short stature, and microcephaly (Klingseisen and Jackson 2011). Previously, partial loss-of-function mutations have been identified in genes encoding fundamental components of the cell cycle machinery, suggesting a model in which disrupted cell proliferation during development results in "hypocellular" forms of dwarfism (Klingseisen and Jackson 2011).

Perturbation of components of the DNA replication machinery has emerged as a common cause of MPD, involving several stages of the replication process. In the G1-phase of the cell cycle the prereplication complex acts to license replication origins, and subsequently the replication preinitiation complex is formed, with the full replisome assembled at S-phase entry, to initiate DNA replication effected by three DNA polymerases: $\alpha, \delta$, and

\footnotetext{
${ }^{7}$ These authors contributed equally to this work.

${ }^{8}$ The full list of The Scottish Genomes Partnership members and their affiliations is given at the end of this article.

Corresponding authors: andrew.jackson@igmm.ed.ac.uk, martin.reijns@igmm.ed.ac.uk

Article published online ahead of print. Article and publication date are online at http://www.genesdev.org/cgi/doi/10.1101/gad.340190.120. Freely available online through the Genes \& Development Open Access option.
}

$\varepsilon(\operatorname{Pol} \alpha, \delta$, and $\varepsilon)$. Biallelic mutations in components of the prereplication complex were first identified, with ORC1, ORC4, ORC6, CDT1, and CDC6, causing MeierGorlin syndrome (MGS) (Bicknell et al. 2011a,b; Guernsey et al. 2011), a disorder defined by a triad of microtia, patella hypoplasia, and growth restriction. Heterozygous stabilizing mutations in GMNN and recessive variants in CDC45, MCM5, and DONSON have subsequently been associated with MGS (Burrage et al. 2015; Fenwick et al. 2016; Reynolds et al. 2017; Vetro et al. 2017). Mutations in, respectively, prereplication complex and preinitiation complex components MCM4 and GINS1 cause distinct microcephalic dwarfism syndromes with immunodeficiency and/or adrenal failure (Gineau et al. 2012; Cottineau et al. 2017). Finally, mutations in genes encoding subunits of the replicative DNA polymerases $P O L A 1$, $P O L D 1, P O L D 2, P O L E$, and POLE2 have implicated components of the active replisome in primordial dwarfism, often with immune deficiency, and in the case of POLE, adrenal failure (Pachlopnik Schmid et al. 2012; Thiffault et al. 2015; Frugoni et al. 2016; Logan et al. 2018; Conde et al. 2019; Van Esch et al. 2019).

(C) 2020 Parry et al. This article, published in Genes \& Development, is available under a Creative Commons License (Attribution 4.0 International), as described at http://creativecommons.org/licenses/by/4.0/. 
Each of these genes has been shown to be essential for cellular survival in large-scale functional screens (Supplemental Table S1; Chen et al. 2017) while constraint metrics from the gnom $\mathrm{AD}$ consortium suggest that loss of a single copy is unlikely to result in developmental disease (Supplemental Table S2; Karczewski et al. 2020). Recessive pathogenic variants are therefore most likely to lead to perturbation of function more severe than haploinsufficiency but falling short of biallelic loss of function. Consistent with this, previously published variants associated with recessive MPD have included hypomorphic missense or splice altering variants that result in at least one allele with residual function. The recent identification of an intronic splice altering mutation in POLE in 12 families exemplifies this, where each affected individual inherited different loss-of-function alleles in trans with the same intronic variant $(c .1686+32 \mathrm{C}>\mathrm{G})$ causing a hypomorphic splicing defect. Hypomorphic alleles such as this may not be annotated as deleterious by variant classifiers, so we considered whether additional genes for MPD could be detected by using a variant classification agnostic approach to identify as yet undiscovered cryptic mutations in essential genes. Here, we report the identification of PRIM1 as an MPD gene, and demonstrate that mutations reduce cellular PRIM1 protein levels, impairing DNA replication.

\section{Results}

\section{Identification of biallelic variants in PRIM1}

We analyzed whole-genome (WGS) and whole-exome (WES) sequence data from 220 families with microcephalic dwarfism spectrum disorders (occipital-frontal circumference $[\mathrm{OFC}] \leq-4 \mathrm{SD}$; height $\leq-2 \mathrm{SD}$ ) to find variants enriched in this cohort relative to the general population and inherited in a pattern consistent with recessive inheritance (Materials and Methods; Supplemental Table S3). This identified three families sharing a homozygous intronic variant $($ c. $638+36 \mathrm{C}>\mathrm{G})$ (Fig. 1A,B) in PRIM1, which encodes the catalytic subunit of DNA primase.

Supporting its pathogenicity, the intronic PRIM1 variant was significantly enriched in our microcephalic dwarfism cohort in comparison with the Genome Aggregation Database where just two heterozygotes out of 141,456 individuals were observed (gnomAD v2.1.1, $P=3.61 \times 10^{-15}$, all populations, combined WES and WGS data) (Supplemental Table S4).

Inbreeding coefficients in all three families were consistent with parental relatedness (Supplemental Table S5) while kinship estimates confirmed the different families were not closely related (Supplemental Table S6). As well, P1-P4 had large overlapping regions of homozygosity between $10.4 \mathrm{Mb}$ and $32.7 \mathrm{Mb}$ in length on chromosome 12 containing the PRIM1 gene (Supplemental Fig. S1). These findings provided additional genetic support for PRIM1 being the causative gene as they were consistent with the expectation for consanguineous families with a rare recessive disease that a disease-causing variant is expected to lie within a region of homozygosity in each family (Lander and Botstein 1987). Within the shared region of homozygosity there was also a common 2-Mb haplotype surrounding the PRIM1 variant in all four affected individuals (Supplemental Fig. S1; Supplemental Table S7). This indicates that all three families share a distant common ancestor (Supplemental Fig. S1; Supplemental Table S5), establishing the causal mutation to be within the haplotype and excluding the only other enriched variant in families 2 and 3, a missense change in OR6C4.

Analysis of the c. $638+36 \mathrm{C}>\mathrm{G}$ variant with SpliceAI (Jaganathan et al. 2019), NNSplice (Reese et al. 1997), and MaxEntScan (Yeo and Burge 2004) predicted activation of a cryptic donor site, resulting in the inclusion of 31 nucleotides of intronic sequence following exon 6 , expected to disrupt the open reading frame. This, alongside PRIM1 function in DNA replication, provided further support for disruption of PRIM1 causing MPD.

To identify additional disease-causing PRIM1 alleles, we searched exome data from a subset of 149 trios and singletons from the Deciphering Developmental Disorders (DDD) Project selected on the basis of morphometric criteria (OFC $\leq-3$ SD and height $\leq-3 \mathrm{SD}$ ) and absence of previous diagnostic variants identified by DDD. This identified a single individual (P5) compound heterozygous for an essential splice donor variant $(\mathrm{c} .103+1 \mathrm{G}>\mathrm{T})$ and a missense variant (c.901T >C, p.Cys301Arg, hereafter referred to as C301R). These variants were extremely rare or absent from public databases, respectively (Table 1). Additional analysis of exome data from P5 did not reveal any other likely diagnostic variants as an alternative explanation. The c.103+1G > T variant results in loss of the donor site of intron 1 while the c.901T>C variant alters a cysteine residue, conserved in vertebrates, to a physiochemically dissimilar arginine. This substitution was predicted damaging by in silico tools including PolyPhen2, SIFT, MutationTaster and CADD (CADDv1.6 Phred score $=28.4$ ).

\section{PRIM1 subjects share a distinct clinical phenotype}

A similar clinical phenotype was evident in all five individuals. All had extreme growth failure, with in utero growth retardation (birth weight $-3.4 \pm 0.6 \mathrm{SD}$ ) and severe postnatal growth restriction (height $-8.8 \pm 2.0 \mathrm{SD}$ ) (Fig. 1C; Supplemental Table S8). While relatively macrocephalic, in absolute terms there was extreme microcephaly (OFC $-6.0 \pm 1.5 \mathrm{SD}$ ). On neuroimaging this was reflected by a "microcephaly with simplified gyri" appearance (Fig. 1D). A common facial appearance was apparent, with prominent forehead and triangular face, with blepharophimosis \pm microphthalmia, micrognathia, and small low-set ears (Fig. 1E). Absence of subcutaneous fat, and distally tapered fingers were noted in all affected individuals on clinical examination. Hypothyroidism was frequent alongside significant haematological/immune dysfunction. All had hypo/agammaglobulinemia (Table 2). In four of five cases there was persistent lymphopenia accompanied by intermittent anemia/thrombocytopenia. Documented episodes of sepsis occurred in several patients. In addition, episodes of fever without an identified infective source were recorded. All individuals had chronic respiratory 


\section{A}

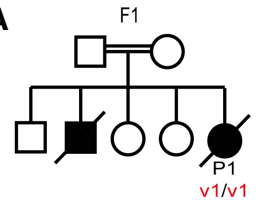

$=$ reference allele $\mathrm{v} 1=\mathrm{c} .638+36 \mathrm{C}>\mathrm{G}$

$2=C .901 T>C$

$\mathrm{v} 3=\mathrm{c} \cdot 103+1 \mathrm{G}>\mathrm{T}$

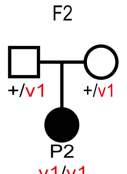

F3

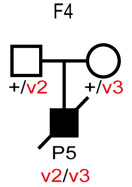

C

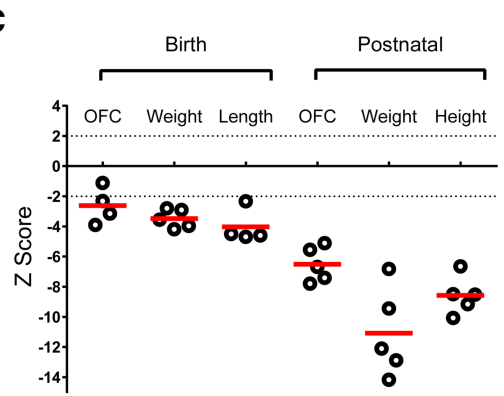

$\mathbf{E}$

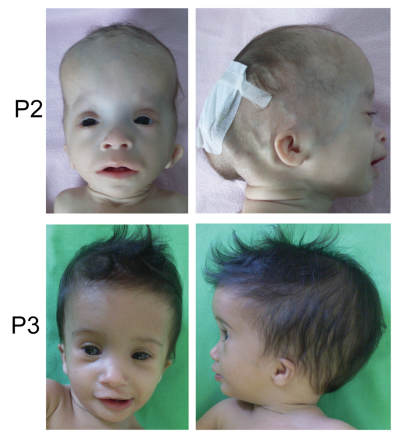

B

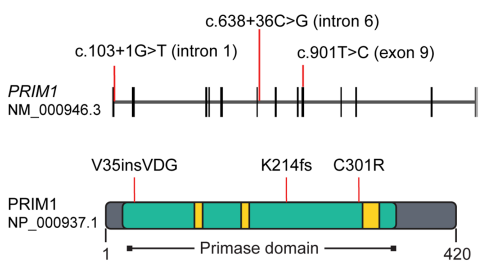

D

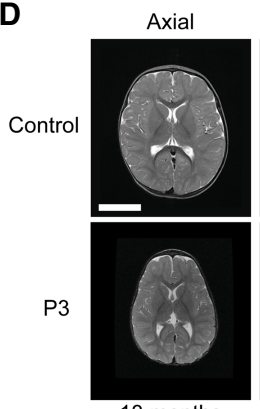

13 months

Figure 1. Individuals with biallelic PRIM1 variants have primordial dwarfism. (A) Family pedigrees with segregation of PRIM1 variants as indicated. (Square) male; (circle) female; (filled symbols) individuals with primordial dwarfism, (strike through) deceased. (B) Schematic of PRIM1 transcript and protein. (Vertical black lines) exons. Locations of variants are indicated by red lines. (Green) Primase domain (NCBI CDD cd04860), (yellow) nucleotide-binding residues. $(C)$ Growth parameters of individuals with PRIM1 deficiency. $Z$ scores (standard deviations from population mean for age and sex). Dashed lines indicate $95 \%$ confidence interval for general population. (Circles) individual subject data points, (red bars) mean values. (D) MRI neuroimaging of P3 demonstrates microcephaly with simplified gyri. Axial T2; Sagittal T1. Comparison with age-matched healthy controls. Scale bar, $5 \mathrm{~cm}$. (E) Photographs of individuals P2P5. (P2) 8 mo, (P3) 7 mo, (P4) newborn, (P5) 7 mo. Written consent was obtained from families for photography.

symptoms, and four died in early childhood from either respiratory or GI infections. Hepatic dysfunction was noted clinically, and at postmortem, hepatic fibrosis, cirrhosis, or macronodular regeneration was evident in three of these individuals, suggesting preceding chronic liver inflammation.

The distinct clinical phenotype in these individuals was consistent with a shared genetic etiology, and taken together with our genetic data, led us to conclude that biallelic mutations in the PRIM1 gene cause MPD. Next, we sought to test the functional impact of the variants identified in PRIM1.

The c. $638+36 C>G$ variant activates a cryptic splice site reducing cellular PRIM1 protein

To confirm that the $c .638+36 \mathrm{C}>\mathrm{G}$ variant resulted in missplicing, RT-PCR was performed on RNA extracted from a lymphoblastoid cell line (LCL) established from individual P2 and from primary fibroblasts cultured from

Table 1. PRIM1 variants identified in individuals with MPD

\begin{tabular}{|c|c|c|c|c|c|c|c|c|}
\hline \multirow[b]{2}{*}{ Family } & \multirow[b]{2}{*}{ Individual } & \multicolumn{3}{|c|}{ Allele 1} & \multicolumn{3}{|c|}{ Allele 2} & \multirow{2}{*}{$\begin{array}{c}\text { Country of } \\
\text { origin }\end{array}$} \\
\hline & & HGVSc & HGVSp & $\mathrm{AF}$ & HGVSc & HGVSp & $\mathrm{AF}$ & \\
\hline 1 & P1 & c. $638+36 \mathrm{C}>\mathrm{G}$ & p.Lys214Serf $s^{*} 21$ & $1.49 \times 10^{-5}$ & c. $638+36 \mathrm{C}>\mathrm{G}$ & p.Lys $214 \operatorname{Ser} f s^{*} 21$ & $1.49 \times 10^{-5}$ & Hungary \\
\hline 2 & $\mathrm{P} 2$ & c. $638+36 \mathrm{C}>\mathrm{G}$ & p.Lys $214 \operatorname{Ser} s_{S} * 21$ & $1.49 \times 10^{-5}$ & c. $638+36 \mathrm{C}>\mathrm{G}$ & p.Lys $214 \operatorname{Serf} s^{*} 21$ & $1.49 \times 10^{-5}$ & Hungary \\
\hline 3 & P3 & c. $638+36 \mathrm{C}>\mathrm{G}$ & p.Lys $214 \operatorname{Ser} f s^{*} 21$ & $1.49 \times 10^{-5}$ & c. $638+36 \mathrm{C}>\mathrm{G}$ & p.Lys $214 \operatorname{Ser} f s^{*} 21$ & $1.49 \times 10^{-5}$ & Hungary \\
\hline 3 & $\mathrm{P} 4$ & c. $638+36 \mathrm{C}>\mathrm{G}$ & p.Lys $214 \operatorname{Ser} f s^{*} 21$ & $1.49 \times 10^{-5}$ & c. $638+36 \mathrm{C}>\mathrm{G}$ & p.Lys $214 \operatorname{Serf}_{s} * 21$ & $1.49 \times 10^{-5}$ & Hungary \\
\hline 4 & P5 & c. $103+1 G>T$ & p.Val35_Ile36insAspGlyVal & $2.03 \times 10^{-5}$ & c. $901 \mathrm{~T}>\mathrm{C}$ & p.Cys301Arg & - & UK \\
\hline
\end{tabular}

Variants reported in this study are described using HGVS nomenclature (https://varnomen.hgvs.org// for the reference coding DNA (HGVSc, NCBI reference sequence NM_000946.3), and protein (HGVSp, NCBI reference sequence NP_000937.1) sequences. The variant allele frequency $(\mathrm{AF})$ for non-Finnish European populations in gnom $\mathrm{AD}$ is given for each variant. DNA variants are expressed relative to the coding ("c.") sequence, and all protein changes are preceded by "p." 
PRIM1 deficiency causes primordial dwarfism

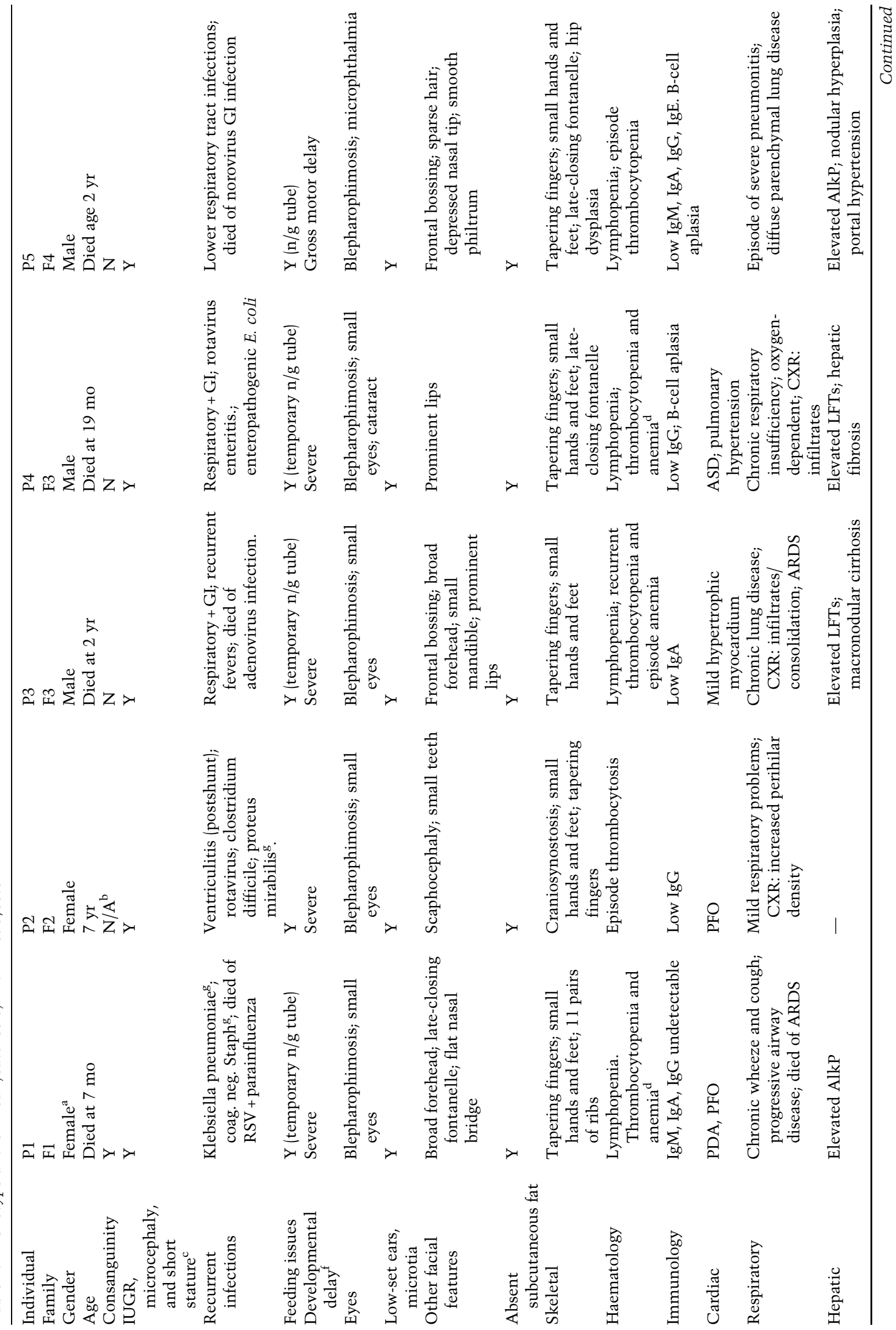


Parry et al.

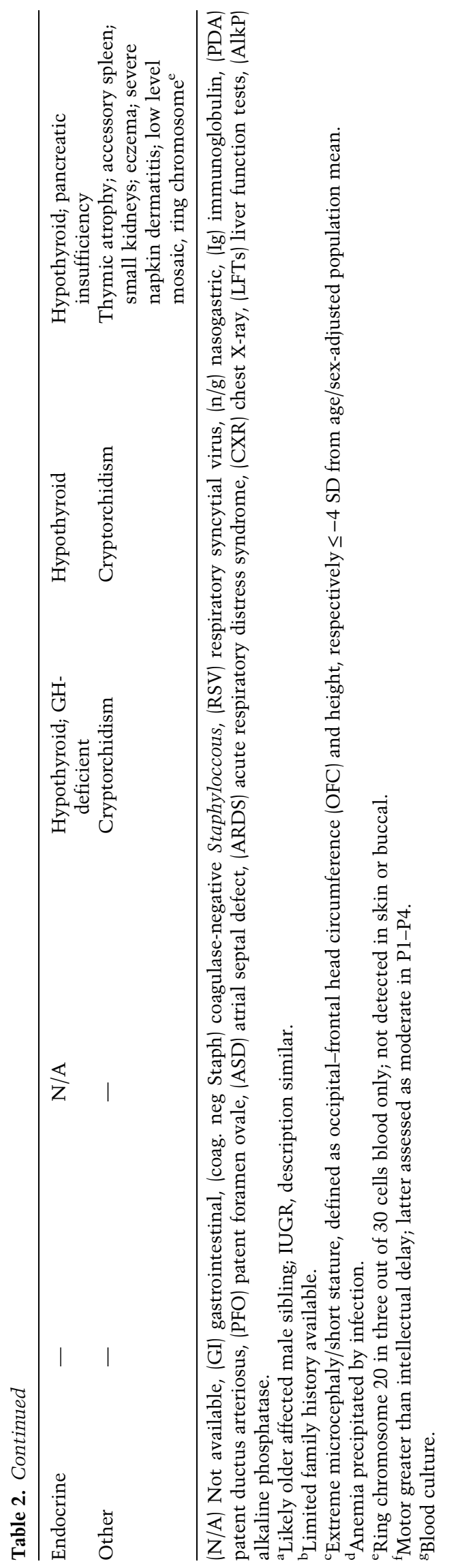


individual P3. This demonstrated the presence of an additional PCR product in P2 and P3 corresponding in size to the predicted misspliced transcript (Fig. 2A). Sanger sequencing of these PCR products confirmed in silico splice predictions, with the presence of an additional $31 \mathrm{nt}$ of intronic sequence (Fig. 2B,C), leading to substitution of a lysine to serine at codon 214 and a frameshift with premature termination 21 amino acids later (HGVS nomenclature: p.Lys214Serfs*21, referred to hereafter as K214fs). This would be anticipated to lead to nonsense-mediated decay (NMD) of this transcript, with any remaining translated truncated protein not containing key catalytic residues and therefore enzymatically inactive (Fig. 1B). Reduced cellular levels of full-length protein were therefore expected, and consistent with this, marked reduction in full-length PRIM1 protein levels was evident on immunoblotting of cell extracts from P2 and P3 in comparison with control cell lines (14\% of wild-type levels in patient LCL and $9 \%$ in fibroblasts) (Fig. 2D). (A band at $25 \mathrm{kDa}$, that might correspond to a nonfunctional truncated PRIM1 protein $[27 \mathrm{kDa}]$, was seen inconsistently in blots from P2 LCL extracts but not in P3 fibroblasts [Supplemental Fig. S2].)

\section{C301R and c. $103+1 G>T$ variants also reduce PRIM1 protein levels}

P5 was compound heterozygous for c.103+1G>T and C301R variants. However, a patient cell line was not available; therefore, the consequences of these variants were assessed by different methodologies. Our initial expectation was that the essential splice site mutation would be a null allele and the missense variant, partial loss of function.

C301 is a residue in a buried hydrophobic region of the protein (Fig. 3A), and its substitution with a bulky, positively charged arginine residue (C301R) was predicted to be highly destabilizing by FoldX (Supplemental Fig. S3; Schymkowitz et al. 2005). We therefore assessed the effect of this substitution on PRIM1 protein levels, developing a FACS-based assay to measure the level of PRIM1-GFP containing this insertion relative to a cotranslated RFP control (Fig. 3B). This approach corrects for cell to cell variation in transfection efficiency and ensures that assessment of protein expression is not confounded by transcriptional differences or mRNA stability. This assay confirmed substantially reduced PRIM1 protein levels for the C301R substitution ( $25 \pm 0.3 \%$ ) (Fig. 3C,D).

We also modeled this mutation in budding yeast, where substitution of the equivalent residue in $S$. cerevisiae Prilp to arginine (L309R) also led to a reduction in protein level (Supplemental Fig. S4), whereas the wild-type human cysteine residue (L309C) had no effect on either the level of Pril protein (Supplemental Fig. S4) or growth (Supplemental Fig. S5). Similar degradation dynamics of wildtype and L309R Prilp in cycloheximide chase experiments (Supplemental Fig. S4) suggest that reduced protein levels are most likely the consequence of incorrect folding of the C301R/L309R protein rather than an increase in turnover. Notably C301 is in close proximity to the key
A

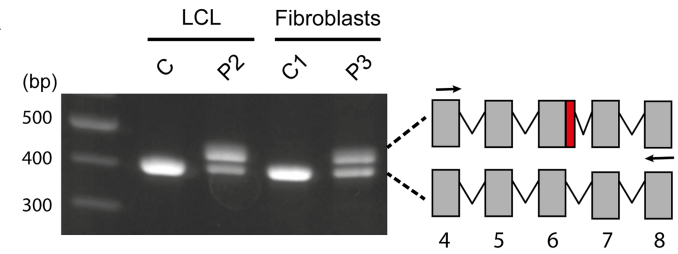

B
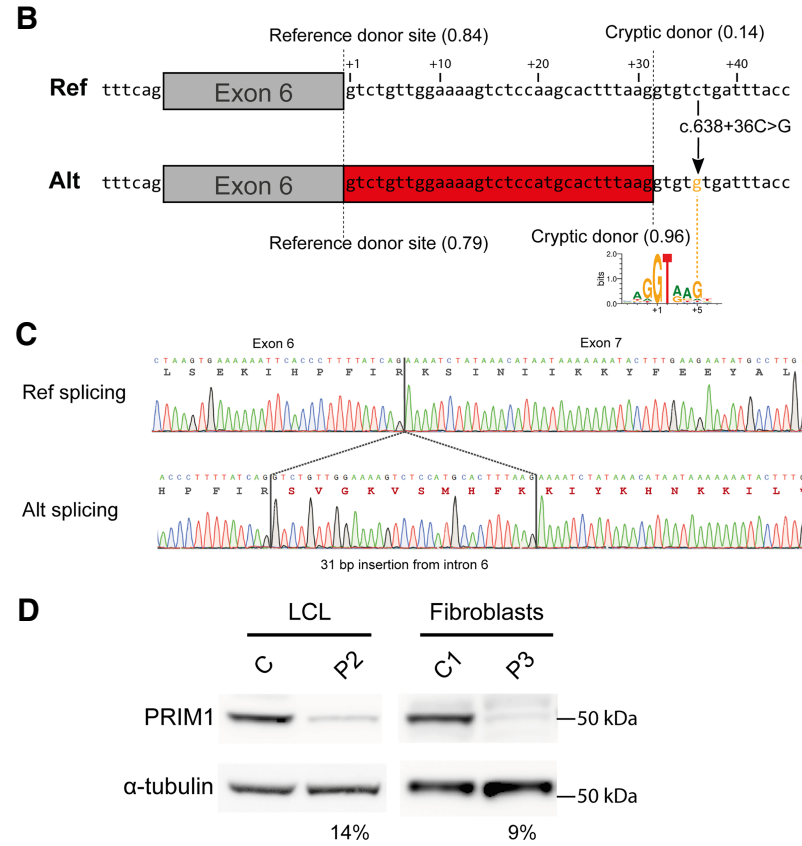

Figure 2. The c. $638+36 \mathrm{C}>\mathrm{G}$ variant creates a cryptic splice donor site, resulting in markedly reduced cellular PRIM1 protein levels. (A) The c. $638+36 \mathrm{C}>\mathrm{G}$ variant alters PRIM1 splicing by creating a cryptic splice donor site in intron 6. RT-PCR of PRIM1 transcripts from lymphoblastoid cells from P2 and primary fibroblasts from P3. Arrows in schematic indicate the position of primers. (Gray boxes) exons, (red box) retained sequence resulting from missplicing. (B) Schematic depicting the effect of the c.638 $+36 \mathrm{C}>\mathrm{G}$ variant on splicing of intron 6 of PRIM1. The reference and alternate sequences of intron 6 shown with positions of reference and cryptic splice donor sites marked by dotted lines. SpliceAI scores for the donor sites are in brackets. Thirty-one nucleotides included as a result of the c. $638+36 \mathrm{C}>\mathrm{G}$ variant are shown on a red background. A sequence logo created with 100,000 randomly selected human U2 splice donor sites from Ensembl (v83) (Cunningham et al. 2015) using WebLogo (Crooks et al. 2004) illustrates how the c. $638+36 \mathrm{C}>\mathrm{G}$ substitution creates a strong splice consensus sequence by providing a $\mathrm{G}$ at the +5 position. (C) Representative Sanger sequencing traces of splice products relating, respectively, to the lower band in $A$ ("ref splicing") and the alternatively spliced upper band ("alt splicing"). (D) PRIM1 protein levels are markedly reduced in cells from individuals $\mathrm{P} 2$ and P3, homozygous for the c. $638+36 \mathrm{C}>\mathrm{G}$ variant. Immunoblots of total cell extracts from lymphoblastoid cells (P2) and primary fibroblasts (P3). a-tubulin, loading control. (C) lymphoblastoid, (C1) fibroblast cell lines from control subjects. Quantification of PRIM1 protein levels for $\mathrm{P} 2$ and $\mathrm{P} 3$ cells relative to $\mathrm{C}$ and $\mathrm{C} 1$ controls, respectively (normalized to a-tubulin loading control), is shown below each blot.

catalytic residue R304 (Kirk and Kuchta 1999), suggesting that it might not solely act to reduce protein levels. 
A

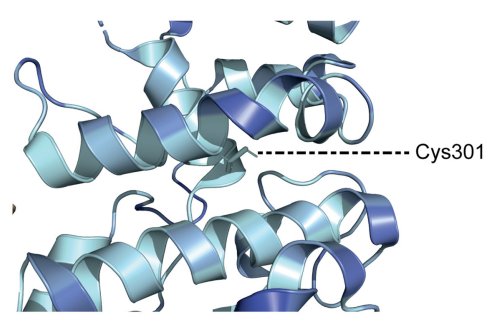

Solvent Accessibility

Buried $\rightleftharpoons$ Exposed

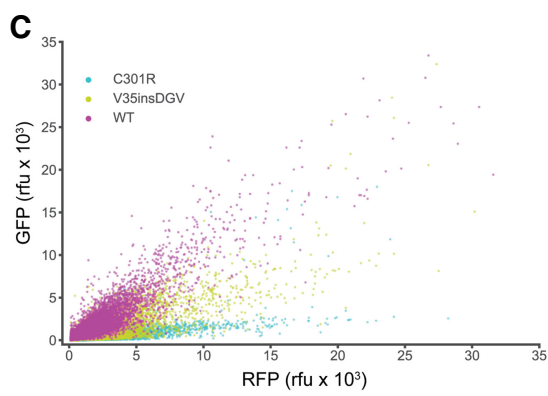

E

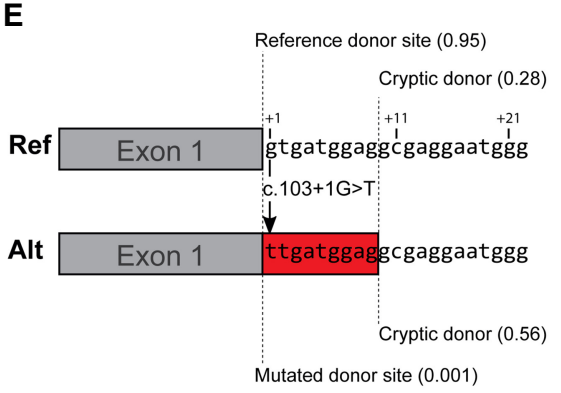

D

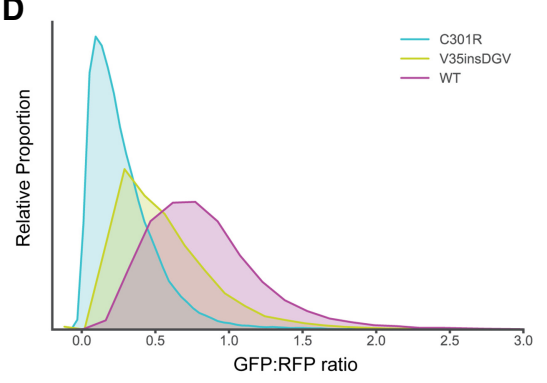

B

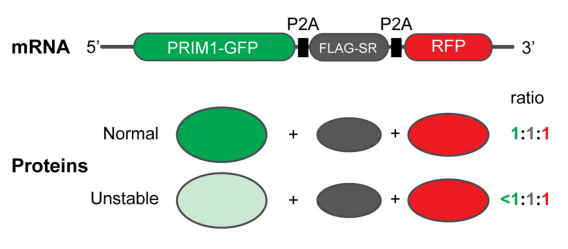

$F$

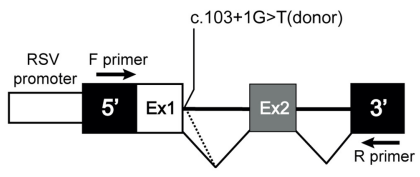

G
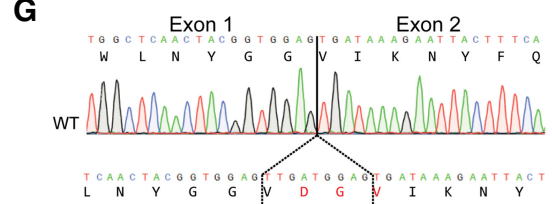

c. $103+1 \mathrm{G}>\mathrm{T}$

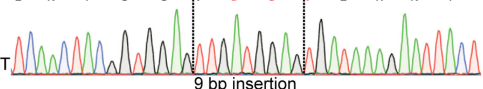

Figure 3. The c.103+1G $>\mathrm{T}$ and $\mathrm{C} 301 \mathrm{R}$ variants reduce PRIM1 protein levels. $(A)$ Cysteine 301, substituted to arginine in P5, lies in a buried hydrophobic region. DNA primase dimer crystal structure (PDB: 4BPU) with residues shaded according to solvent accessibility. (B) Schematic of the FACSbased dual-reporter stability assay. Expression vector expresses an mRNA encoding PRIM1-GFP-P2A-FLAG-SR-P2A-RFP. Intervening P2A "self-cleaving" peptide sequences produce PRIM1-EGFP, FLAG-SR, and RFP polypeptides in equimolar amounts. PRIM1-GFP (wild type and mutants) and RFP levels are assayed in individual cells by flow cytometry. PRIM1-GFP and FLAG-SR levels can be independently assessed by immunoblotting (see Supplemental Fig. S3D). (C) GFP-RFP scatter plot for wild-type, C301R, and V35insDGV dual reporter constructs. $n=\mathrm{WT}, 27,027$; C301R, 44,863; V35insDGV 46,441 cells respectively. (rfu) Relative fluorescence units. $(D)$ Kernel density estimation plot of GFP: RFP ratios from C. (E) Schematic depicting the consequence of the $c .103+1 \mathrm{G}>\mathrm{T}$ variant on splicing. Reference and alternate sequences of intron 1 are shown with positions of the reference and cryptic splice donor sites marked by dotted lines. SpliceAI scores for splice donor sites in brackets. (Red box) Nine nucleotides of intron 6 included as a result of activation of the cryptic splice donor variant. $(F)$ Schematic assaying the effect of the c.103+1G>T variant. Minigene assay. DNA spanning exon 1 (Ex1) and exon 2 (Ex2) of PRIM1 was cloned into the minigene. (Arrows) Position of PCR primers, (dotted line) splicing from cryptic splice donor. $(G)$ Representative cDNA Sanger sequence traces from wildtype (WT) and c.103+1G>T variant minigene constructs. The three-amino-acid (DGV) insertion from the c.103+1G $>\mathrm{T}$ variant marked in red.

Consistent with this, the L309R mutation was lethal in yeast (Supplemental Fig. S5), raising the possibility that C301R in human PRIM1 is also a null allele, as disturbance of this catalytic site could potentially lead to loss of function in any mutant protein that persists in the cell.

The C301R substitution appeared to be of greater functional severity than expected, so we examined the c. $103+1 \mathrm{G}>\mathrm{T}$ variant in more detail, considering whether it might instead be hypomorphic in effect. Consistent with this possibility, a minigene assay established that the c.103+1G>T variant could lead to the use of a nearby cryptic splice site (Fig. 3E; Supplemental Fig. S6) resulting in a three-amino-acid in-frame insertion in the PRIM1 transcript ("V35insDGV") (Fig. 3F,G). The FACS-based stability assay established that the V35insDGV insertion also lowers PRIM1 protein levels $(52 \pm 0.5 \%$ of wild-type levels) (Fig. 3C,D), but less severely than C301R, consistent with this being a partial loss of function mutation.
In conclusion, these experiments confirmed that both variants have functional impact on the PRIM1 protein, that in combination would still leave residual PRIM1 activity.

\section{Fork stability and origin firing is impaired in PRIM1 primary fibroblasts}

Human PRIM1 encodes the $49 \mathrm{kDa}$ catalytic subunit of the DNA primase heterodimer, which forms a heterotetrameric complex with the two DNA polymerase a subunits (Czechowska and Błasiak 2005). PRIM1 is responsible for the synthesis of short RNA primers required for the initiation of DNA replication and Okazaki fragment synthesis, before handover of these primers to Pol a for DNA synthesis (Rowen and Kornberg 1978; Frick and Richardson 2001). As such, depletion of PRIM1 would be expected to impact the efficiency of DNA replication. 
Doubling times of P3 primary fibroblasts were significantly increased compared with controls $(\mathrm{P} 3=49 \pm 3.6 \mathrm{~h}$, $\mathrm{C} 1=23 \pm 2.9 \mathrm{~h}, \mathrm{C} 2=27 \pm 2.3 \mathrm{~h}, P<0.001$ ) (Fig. 4A), and Sphase length, measured by sequential CldU/IdU pulse labeling (Martynoga et al. 2005), was substantially increased $(\mathrm{P} 3=16.6 \pm 0.12 \mathrm{~h}, \mathrm{C} 1=6.1 \pm 0.4 \mathrm{~h}, \mathrm{C} 2=7.2 \pm 1 \mathrm{~h})$ (Fig. 4B, C). Complementation by transient transfection of wildtype, but not C301R mutant PRIM1 confirmed that the lengthened S-phase was specifically due to PRIM1 deficiency in patient cells (Fig. 4D,E). Impaired efficiency of DNA replication was also observed in BrdU-DNA content flow cytometry, which demonstrated reduced BrdU incorporation in P3 primary fibroblasts during $S$ phase compared with control fibroblast lines $(P<0.001)$ (Fig. 4F,G).
In addition, $\gamma \mathrm{H} 2 \mathrm{AX}$ levels, a marker of DNA damage, were significantly increased in patient fibroblasts during $S$ phase (Fig. 4H), as were levels of chromatin bound RPA (Supplemental Fig. S7), consistent with the presence of endogenous replication stress. However, whether S-phase checkpoint activation occurs remains to be determined.

FACS analysis of the cell cycle also demonstrated an increased proportion of G1-phase cells (Fig. 4F; Supplemental Fig. S8), without significant differences in the fraction of cleaved caspase-3- or p21-positive patient cells (Supplemental Fig. S9). We therefore concluded that the hypoproliferative phenotype was most likely the consequence of delayed cell cycle progression rather than increased apoptosis or cell cycle exit.
A

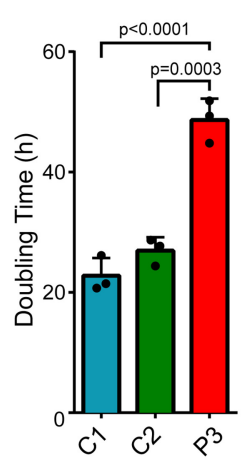

$\mathbf{F}$
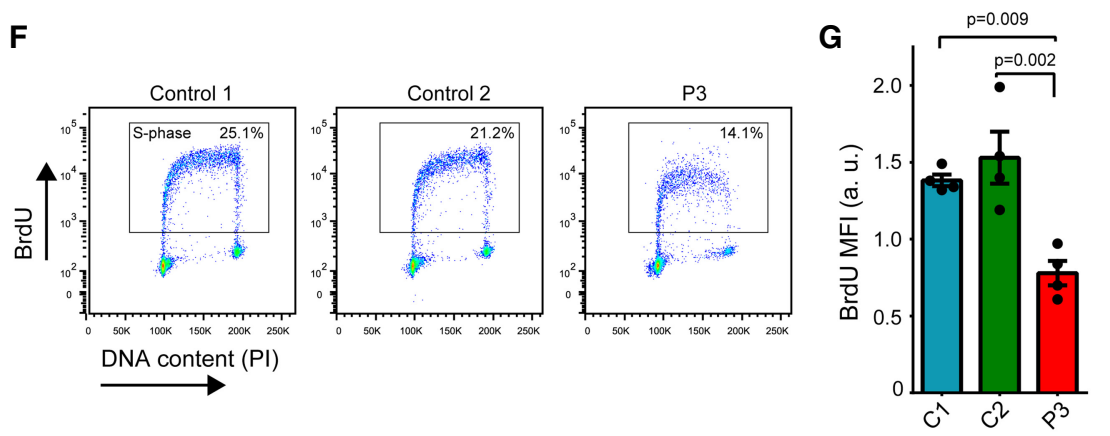

H

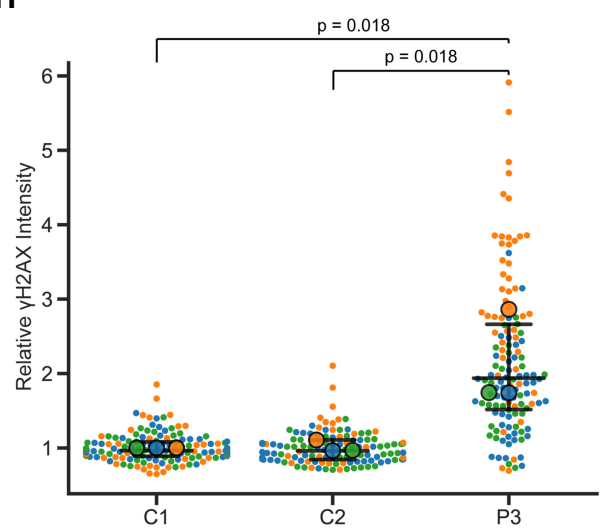

I

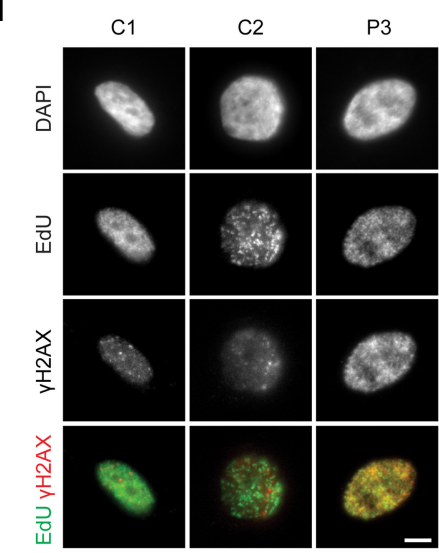

D

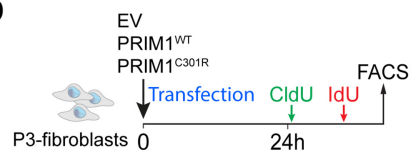

C

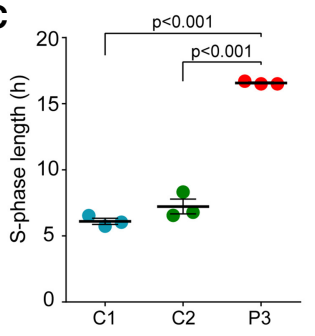

E

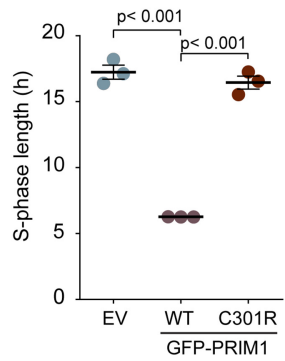

B
Figure 4. Reduced cell proliferation and impaired DNA replication in PRIM1-deficient primary fibroblasts. $(A)$ Cell doubling time plotted for three independent experiments on P3 and two unrelated control C1 and $\mathrm{C} 2$ primary fibroblast cell lines. Bars indicate the mean. Error bars indicate SD. $(B)$ Schematic of CldU/IdU double-pulse experiment used to determine S-phase time. Cells were labeled with CldU at $\mathrm{t}=0$, followed by IdU after $1.5 \mathrm{~h}$. Cells leaving $\mathrm{S}$ phase $\left(\mathrm{L}_{\text {cells }}\right)$ are labeled with CldU only, while cells remaining in $S$ phase $\left(\mathrm{S}_{\text {cells }}\right)$ are labeled with both CldU and IdU. (Ts) Sphase length, the product of interval between pulses (Ti) and the proportion of $S_{\text {cells }}$ to $\mathrm{L}_{\text {cells }}$ (Martynoga et al. 2005). (C) S-phase time is substantially increased in P3 fibroblasts compared with controls. Mean \pm SEM, $N=3$ experiments. (D) Schematic of rescue experiment. P3 fibroblast transfected with either empty vector (EV), wildtype (WT) or C301R-PRIM1-GFP as indicated and after $24 \mathrm{~h} \mathrm{~S}$-phase time determined as in $B$ for GFP + ve cells. $(E)$ Complementation with WT PRIM1-GFP rescues slow Sphase progression in P3 fibroblasts. S-phase length plotted for $n=3$ experiments. Mean \pm SEM. $(F)$ DNA content and BrdU flow cytometry scatter plots, representative of four independent experiments on control $(\mathrm{C} 1$ and C2) and P3 primary fibroblast cell lines. $(G)$ BrdU incorporation is reduced in PRIM1-deficient cells during S-phase. Quantification of BrdU mean fluorescence intensity (MFI) from control and patient-derived fibroblasts according to S-phase gate in $F$. (a.u.) Arbitrary units. $(H) \gamma-\mathrm{H} 2 \mathrm{AX}$ is increased in S-phase P3 fibroblasts. Mean $\gamma$ $\mathrm{H} 2 \mathrm{AX}$ intensity calculated for EdU-positive nuclei from $\mathrm{C} 1, \mathrm{C} 2$, and $\mathrm{P} 3$ cells. $n=3$ experiments. Data points are colored by experiment. (Filled circles) Mean values for each replicate, (bars) median and interquartile range (all values). Values were normalized for each experiment relative to $\mathrm{C} 1$ mean value. ( $P$-values) Repeat measures ANOVA with Tukey multiple comparison test. $(I)$ Representative immunofluorescence images of S-phase nuclei quantified in $H$. Scale bar, $5 \mu \mathrm{m}$. Statistics in $A, C, E$, and $G$ are one-way ANOVA with Tukey multiple comparison test. 
We used DNA fiber combing to further characterize replication defects in PRIM1-deficient patient cells. Primary fibroblasts from P3 demonstrated similar replication defects to fibroblasts from an individual with POLE-IMAGe syndrome caused by Pol $\varepsilon$ deficiency (P1 from Logan et al. 2018). Fork speed was not affected in either PRIM1- or POLE-deficient cell lines (Fig. 5B), but both cell lines displayed a similar, high degree of perturbed fork-progression compared with controls (Fig. $5 \mathrm{C})$, indicative of elevated fork stalling and restart events, as might be expected for an enzyme continually required for priming of Okazaki fragments during lagging strand synthesis. Increased interorigin distances were also observed (median IOD $152 \mathrm{~kb}$ vs. $113 \mathrm{~kb}, P<0.001$ ) (Fig. 5D), suggesting reduced DNA replication initiation at origins. These alterations in replication dynamics were similarly observed in P2 LCLs (Supplemental Fig. S10).

Taken together, these findings were consistent with impaired replication fork formation and increased replication fork stalling in PRIM1-deficient cells.

\section{Discussion}

We report here the identification of five individuals with biallelic deleterious variants in PRIM1 using a variant classification independent approach. PRIM1 is essential to cellular survival (Chen et al. 2017) and, like other replisome components, knockout in mice is lethal during embryogenesis (Blake et al. 2011). Mutations in essential genes that result in developmental disorders are necessarily hypomorphic alleles. Identification of such variants is challenging, particularly as they may often be in noncoding regions (Cottineau et al. 2017; Logan et al. 2018; Tarnauskaitè et al. 2019). Consequently, they may not appear on variant lists filtered by functional consequence. Therefore, the agnostic approach used in this study may have utility for the identification of further genes for other Mendelian diseases.

PRIM1 deficiency results in similar growth restriction to other replication-associated disorders such as those associated with Pol $\alpha$ and Pol $\varepsilon$ deficiency (Supplemental Figs. S11, S12). Microtia and lymphopenia are also
A

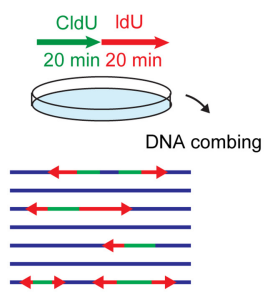

C

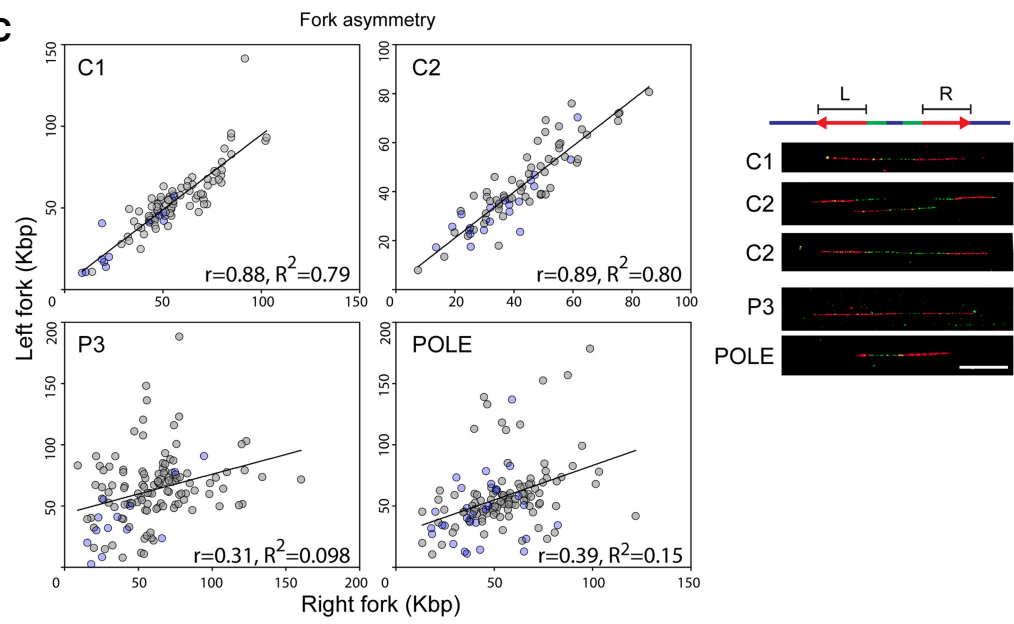

D

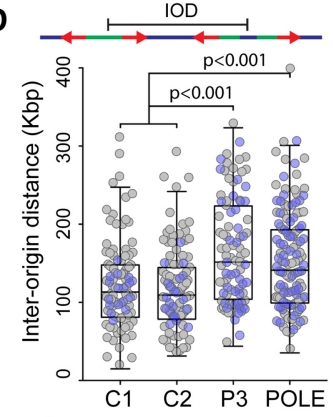

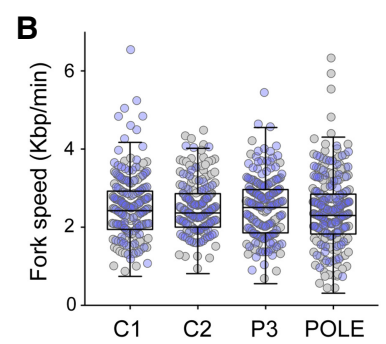

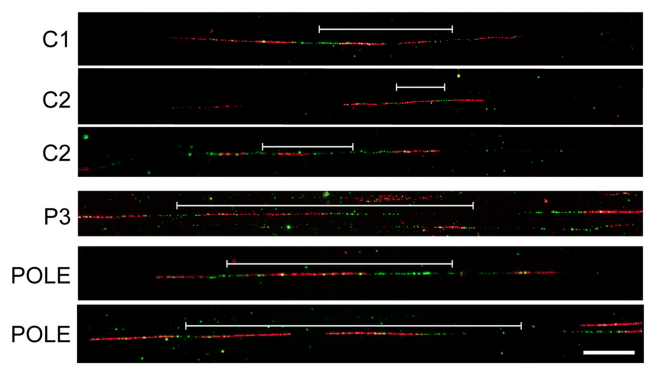

Figure 5. PRIM1 deficiency causes fork asymmetry and increased interorigin distances, consistent with replication fork stalling and decreased replication initiation. (A) Schematic depicting DNA combing experiments. Sequential 20 min CldU and IdU pulses were performed on cultured primary fibroblasts, which were then harvested, with DNA combing performed to characterize DNA replication at the single-molecule level. (B) DNA fork speed, kilobases per minute, in primary fibroblasts from two unrelated control individuals $\mid \mathrm{Cl}$ and C2), a PRIM1-deficient individual (P3), and a POLE-deficient individual. $(B-D)$ Gray and blue dots represent measurements from $n=2$ respective independent experiments. $(C)$ PRIM1-deficient cells exhibit fork asymmetry, similar to POLE-deficient cells. Left (L) versus right (R) fork ratio scatter plots. (r) Pearson correlation coefficient. (Right) Representative images of bidirectional forks. Scale bar, $20 \mu \mathrm{m}$. (D) Interorigin distance (IOD) in control, PRIM1-deficient, and POLE-deficient primary fibroblasts; box plots were graphed according to Tukey method (B,D). P-values, Kruskal-Wallis test. $($ Right $)$ Representative images of IODs. Scale bar, $20 \mu \mathrm{m}$. 
reminiscent of other replisome disorders (Logan et al. 2018; Conde et al. 2019). Likewise, reduced subcutaneous fat in PRIM1-deficient individuals parallels the lipodystrophy found in POLD1 cases (who had normal growth) due to heterozygous single-codon deletion of the catalytic site of Pol $\delta$ (Weedon et al. 2013). However, there are distinctive clinical features for individuals with PRIM1 deficiency, particularly early childhood mortality occurring in four out of five cases. While this might be accounted for by the significant B-cell lymphopenia and accompanying hypo/agammaglobinemia, other disease processes may have also contributed. Chronic lung disease, recurrent diarrhea, and liver dysfunction could also reflect a persisting inflammatory state. Notably a specific intronic variant in POLA1 causing an X-linked reticulate pigmentary disorder, is also associated with recurrent pneumonias and chronic diarrhea, with underlying immunodeficiency alongside autoinflammation (Starokadomskyy et al. 2016). However, the POLA1 associated reticulate pigmentary skin phenotype is not reported in any of the individuals with PRIM1 variants identified herein. Most individuals with MPD caused by POLA1 variants have growth retardation and microcephaly without such features (Van Esch et al. 2019), and facially PRIM1 deficiency appears distinct from these and individuals with POLE-associated IMAGe syndrome (Logan et al. 2018). Likewise, blepharophimosis, microphthalmia, hypothyroidism, episodic thrombocytopenia, and anemia do not appear to be features reported in other replisome disorders.

In conclusion, we describe a distinct form of microcephalic dwarfism associated with PRIM1 mutations. Similar to POLE/A1 DNA polymerase disorders, fork defects are seen in PRIM1-deficient cells (Bellelli et al. 2018; Van Esch et al. 2019). This likely reflects an inability of these cells to establish sufficient replication origins and sustain lagging strand synthesis at a sufficient rate to meet the demand for rapid replication. The ensuing delay to the cell cycle and reduced cellular proliferation provides a likely mechanism for the resulting "hypocellular" microcephalic dwarfism. Given the necessity of several polymerases to act in concert in every replicating cell, the different phenotypic manifestations of Pol $\alpha-$, Pol $\delta$-, Pol $\varepsilon-$, and DNA primase-related disorders are surprising and require future investigation.

\section{Materials and methods}

Research subjects

Genomic DNA was extracted from blood samples by standard methods or from saliva samples using Oragene collection kits according to the manufacturer's instructions. Informed consent was obtained from all participating families. This study was approved by the Scottish Multicentre Research Ethics Committee (REC; 05/MRE00/74). Parents provided written consent for the publication of photographs of the affected individuals.

The DDD study has UK Research Ethics Committee approval (10/H0305/83, granted by the Cambridge South REC, and GEN/ 284/12 granted by the Republic of Ireland REC).
Whole-genome sequencing and variant calling

Whole-genome sequencing for P1, P2, and P4 was performed by Edinburgh Genomics (Clinical Division) as part of the Scottish Genomes Project (SGP) to $30 \times$ coverage using TruSeq nano library preparation kits and a HiSeq X sequencing platform (Illumina). FastQs generated by Edinburgh Genomics were aligned to the human genome (hg38, including alt, decoy, and HLA sequences) using bwa mem (0.7.13) (Li 2013). Postprocessing was performed with samblaster (0.1.22) (Faust and Hall 2014) to mark duplicate reads, and the genome analysis toolkit (GATK, v3.4-0g7e26428) (McKenna et al. 2010) for indel realignment and base recalibration. Genotype likelihoods for each sample were calculated using the GATK HaplotypeCaller and resulting GVCF files were called jointly using GATK's GenotypeGVCFs function. Variant quality score recalibration (VQSR) was performed as per GATK best-practices (Van der Auwera et al. 2013) and a truth sensitivity threshold of $99.9 \%$ was applied. Functional annotations were added using Ensembl's Variant Effect Predictor (v90) (McLaren et al. 2016).

Variant filtering and identification of a variant activating a cryptic splice donor in PRIM1

Cohort WGS variant data were filtered to only include variants with an allele frequency $<0.5 \%$ in all gnom $\mathrm{AD}$ populations at biallelic sites outside of repeat masked or low-complexity regions using VASE (v0.1, https://github.com/david-a-parry/vase). Remaining variants were analyzed against gnomAD v2.1 data converted to hg38 coordinates.

Where variants were present in gnomAD WES and WGS VCFs, allele counts per population were extracted from VCFs. For variants absent from either or both gnomAD WES or WGS VCFs, homozygous reference allele counts were derived for the respective samples using sequencing depth data, where the fraction of individuals with sequencing depth of $\geq 5$ were counted as homozygous reference. Variants were annotated with $P$-values from one-tailed Fisher's exact tests comparing the alternate/reference allele counts in nonrelated affected individuals in the MPD cohort versus individual population groupings in gnomAD.

Annotated variants were assessed for segregation consistent with recessive inheritance. At least one allele was required to have $P$-values $<5 \times 10^{-5}$ for each of the African/African American, Latino/Admixed American, East Asian, Finnish, non-Finnish European, and South Asian gnomAD subpopulations. The second allele for a gene was required to either match these same criteria or to be a predicted loss-of-function variant. Analysis was restricted to canonical transcripts and biallelic combinations of alleles observed in nonaffected family members were excluded. Where available, phase information from parental genotypes and/or physical phasing was used to exclude biallelic combinations in cis.

This enrichment strategy could be confounded by differing variant calling sensitivity in gnomAD compared with the MPD cohort and by population stratification. In order to mitigate these effects we required enriched alleles to be below the given $P$-value threshold in each of the population groups listed above and then ranked genes based on incidental occurrences of variants within the MPD cohort, gene essentiality, and the maximum (least significant) observed $P$-value. Incidental occurrences were defined as the number of families where an individual was a carrier for a variant, yet no qualifying second allele was observed in the affected individual(s). Additionally, more than two qualifying alleles in the same family were also defined as incidental occurrences to address the presence of "noisy" genes. Gene essentiality was defined as the fraction of studies in OGEE /Chen et al. 
2017) in which a gene was found to be cell-essential. A ranking score for variants was calculated as follows: $s=(1+o i)(1+f i)(1.1$ - ess), where " $O i^{\prime}$ indicates the number of incidental occurrences in other families, " $f i^{\prime}$ indicates the number of incidental occurrences within the same family, and "ess" represents the fraction of studies in which the gene is considered cell essential. A lower score was considered "better" such that variants were penalized for incidental occurrences and lack of evidence for gene essentiality.

These methods were implemented in a Python package (ReVERSe), available at https://git.ecdf.ed.ac.uk/dparry/reverse.

\section{Segregation filtering of DDD CAPS14 cohort}

VASE (v0.1, https://github.com/david-a-parry/vase) was used to perform variant filtering and segregation analysis. Variants overlapping PRIM1 were filtered to remove those with a frequency $>0.5 \%$ in gnomAD or dbSNP151. Additionally, those variants not predicted to be either protein-altering variants, within a splice region, or with a SpliceAI (Jaganathan et al. 2019) $\delta$ score $\geq 0.5$ were also excluded. Genotype calls were filtered if samples had fewer than five reads covering the site or the fraction of variant reads to total reads (VAF) were $<0.25$. Remaining variants were assessed for familial segregation consistent with recessive inheritance.

Following identification of PRIM1 compound heterozygous variants in F5, variant data for this family were reanalyzed to test exome-wide for any other possible causative variants. Data for this family were analyzed exome-wide for recessive variants as above and also analyzed for de novo variants, requiring a VAF of $\geq 0.25$ in the proband and VAFs of $<0.05$ in both parental genotypes and total site depths of $\geq 8$ in parents and proband.

\section{Plasmid construction}

All oligonucleotides and plasmids used in this study are listed in Supplemental Tables S9 and S10, respectively. Plasmids pMAR780 and pMAR781 were generated by cloning annealed oligonucleotides into BclI/SwaI-digested pML104 and pML107 plasmids, respectively (Laughery et al. 2015). To construct pMAR782, the PRI1 (YIR008C) coding sequence, without stop codon and with a silent PAM site mutation (c.1945G >C), was amplified by PCR using MRY201 genomic DNA as template and cloned into XbaI/BamHI digested pGFP-C-FUS (Niedenthal et al. 1996). pMAR782 allows expression of C-terminally GFPtagged Pril protein in medium lacking methionine. To construct pMAR790, a 1.35-kb fragment of human genomic DNA (chr12:56750975-56752323, hg38) covering PRIM1 exon 1 and exon 2 was PCR-amplified and cloned into BspEI/XbaI sites of RHCglo (a gift from Thomas Cooper; Addgene plasmid 80169) (Singh and Cooper 2006), fusing PRIM1 exon 1 with exon 1 of the minigene construct. The donor $(\mathrm{c} .103+1 \mathrm{G}>\mathrm{T})$ splice site mutation was introduced in intron 1 using site-directed mutagenesis (NEB Q5 site-directed mutagenesis kit), generating pMAR793. Human C-terminally EGFP-tagged PRIM1 was synthesized by IDT flanked by NheI and BspEI sites and provided in pUCIDTAMP GoldenGate (pMAR796). The NheI/BspEI fragment was then transferred into pmGFP-P2A-K0-P2A-RFP (a gift from Ramanujan Hegde; Addgene plasmid 105686) (Juszkiewicz and Hegde 2017), replacing mGFP and creating pMAR797. To introduce C301R and VDGins mutations, Q5 SDM was performed on pMAR796, creating pMAR798 and pMAR802, respectively, and the sequence-verified PRIM1-EGFP NheI/BspEI fragments cloned into pmGFP-P2A-K0-P2A-RFP to make pMAR799 and
pMAR803. All plasmids were confirmed by restriction digest analysis and Sanger sequencing.

\section{Cells and cell culture}

Primary dermal fibroblasts were established from skin punch biopsies and maintained in AmnioMAX medium (Thermo Fisher Scientific 17001074) in 5\% $\mathrm{CO}_{2}$ and $3 \% \mathrm{O}_{2}$. Patient lymphoblastoid cell lines (LCLs) were generated in house from peripheral blood samples by EBV transformation using standard methods. LCLs were maintained in RPMI 1640 supplemented with 15\% FBS, L-glutamine, and penicillin/streptomycin antibiotics. HeLa (ATCC) cells were maintained in DMEM supplemented with $10 \%$ FBS and $5 \%$ penicillin/streptomycin in $5 \% \mathrm{CO}_{2}$, under normoxic conditions. Genotypes of patient cells lines were validated by Sanger sequencing.

\section{RT-PCR}

Total RNA was extracted from cell lines using the RNeasy minikit (Qiagen) according to the manufacturer's instructions. Following DNase I (Qiagen) treatment cDNA was generated using SuperScript III reverse transcriptase (Thermo Fisher Scientific). RT-PCR was performed on cDNA using primers in exons 4 and 8 (Supplemental Table S9).

\section{Minigene splicing assay}

RPE 1 cells were seeded $\left(4 \times 10^{5}\right.$ cells/well) in a six-well plate. After $24 \mathrm{~h}$, cells were transfected with $800 \mathrm{ng}$ of pMAR790 or pMAR791 plasmid in Opti-MEM Reduced Serum Medium with Lipofectamine 2000 according to the manufacturer's instructions. Cells were harvested after $24 \mathrm{~h}$, RNA extracted using the RNeasy Mini Kit (Qiagen), and cDNA generated using SuperScript III reverse transcriptase (Invitrogen). PCR amplification was then performed with RSV5U and RTRHC primers, and wild-type and mutant cDNA amplicons resolved by agarose gel electrophoresis to visualize splicing differences. PCR products were cloned into pGEM-T Easy (Promega), and Sanger sequencing was performed on 20 clones.

\section{Immunoblotting}

Whole-cell extracts were prepared by lysis using $50 \mathrm{mM}$ Tris- $\mathrm{HCl}$ (pH 8), $280 \mathrm{mM} \mathrm{NaCl}, 0.5 \%$ NP40, 0.2 mM EGTA, 1 mM DTT, and $10 \%$ glycerol, supplemented with Roche Complete protease inhibitor cocktail. Protein samples were resolved on $4 \%-12 \%$ NuPAGE Bis-Tris gels (Thermo Fisher Scientific) and transferred to nitrocellulose or PVDF membranes. Subsequent immunoblotting was performed using the following antibodies: anti-p48 Primase (8G10; 1:1000; Cell Signaling 4725), anti-Vinculin (hVIN$1 ;$ 1:2000; Sigma-Aldrich, V9264), anti- $\alpha$-Tubulin (B-5-1-2; 1:10,000; Sigma-Aldrich, T6074), anti-GFP (Living Colors JL-8; 1:4000; Clontech), anti-FLAG (M2; 1:2000; Sigma-Aldrich F1804), or anti-Actin (1:4000; Sigma-Aldrich A2066).

Finally, detection was performed using Amersham ECL Prime Western blotting detection reagent on the ImageQuantLAS4000 (GE Healthcare Life Sciences), or the Odyssey CLx imaging system (LI-COR Biosciences). Quantifications were performed using ImageQuant TL 7.0 and Image Studio Lite 5.2, respectively.

\section{FACS-based dual-reporter stability assay}

C-terminally EGFP-tagged PRIM1 (wild type or mutants) was cloned into a mammalian expression vector as described under 
Plasmid Construction. Expression from the CMV promoter of the resulting constructs (pMAR797 and derivatives) produces mRNA encoding PRIM1-EGFP-P2A-FLAG-SR-P2A-RFP, which when translated due to intervening P2A "self-cleaving" peptide sequences produces three individual polypeptides in equimolar amounts: PRIM1-EGFP, FLAG-SR, and RFP. This allows comparison of the relative level of PRIM1-EGFP (wild-type and mutants) and RFP in individual cells.

RPE1 cells were seeded $\left(4 \times 10^{5}\right.$ cells/well $)$ in a six-well plate, and a day later transfected with $2 \mu \mathrm{g}$ of the reporter plasmid in Opti-MEM reduced serum medium with Lipofectamine 2000 per the manufacturer's instructions. At $24 \mathrm{~h}$ after transfection, live cells were assayed for the presence of GFP and RFP using a BD Biosciences LSR Fortessa flow cytometer and data were analyzed using FlowJo software (v7.6.1, Tree Star).

\section{BrdU-DNA content flow cytometry}

Primary fibroblasts were seeded into AmnioMAX medium (Life Technologies) to achieve $\sim 60 \%$ confluency after $24 \mathrm{~h}$. Cells were then incubation with $10 \mu \mathrm{M}$ BrdU for $30 \mathrm{~min}$, washed, harvested, and fixed with $70 \% \mathrm{EtOH}$ for $16 \mathrm{~h}$ at $-20^{\circ} \mathrm{C}$. Fixed cells were then digested with $1 \mathrm{mg} / \mathrm{mL}$ pepsin, denatured in $2 \mathrm{M} \mathrm{HCl}$ for $15 \mathrm{~min}$, and washed with PBS. After blocking in 0.5\% BSA and 0.5\% Tween-20, BrdU labeling was detected using anti-BrdU antibody (1:75; Abcam ab6326) and anti-rat Alexa fluor 488 secondary antibody (Thermo Fisher Scientific A11006). DNA content was determined by costaining with $50 \mu \mathrm{g} / \mathrm{mL}$ propidium iodide. Cells were assayed on a BD Biosciences LSR Fortessa flow cytometer and data were analyzed using FlowJo software (v7.6.1, Tree Star).

\section{Cell proliferation doubling times}

Primary fibroblasts $\left(1.5 \times 10^{5}\right.$ cells $)$ were seeded on day 0 into a T25 flask. Cell counts were performed every $3 \mathrm{~d}$ using a MOXI $\mathrm{Z}$ Mini automated cell counter (MXZ001). After counting, 1.5× $10^{5}$ cells were reseeded into a new T25. Doubling times were calculated during log-phase growth (day 3 to day 12) using the formula $t / \log _{2}(e / b)$, where $t=$ time in hours, $e=$ final population size, and $b=$ population size at the start of $\log$ phase growth.

S-phase time measurements and PRIM1 complementation (CldU/IdU pulse labeling)

S-phase time (Ts) measurements were performed using sequential pulses of CldU and IdU to determine the fraction of cells that leave S-phase in a specified time window, according to the formula $\mathrm{Ts}=\mathrm{Ti}^{*} \mathrm{~S}_{\text {cells }} / \mathrm{L}_{\text {cells, }}$, where Ti represents the time (hours) between pulses, $\mathrm{S}_{\text {cells }}$ are the number of cells that are in $\mathrm{S}$ phase at the second pulse (all double-positive), and $\mathrm{L}_{\text {cells }}$ are the number of cells that have left S-phase at the time of the second pulse (CldU-positive and IdU-negative cells).

Primary fibroblasts, cultured on coverslips, were pulsed with $25 \mu \mathrm{M}$ CldU for $1.5 \mathrm{~h}$, followed by a $30-\mathrm{min} 125 \mu \mathrm{M}$ IU pulse. Cells were then fixed in $4 \%$ PFA.

For complementation experiments, P3 fibroblasts were electroporated with dual expression vectors (pmGFP-P2A-K0-P2A-RFP, pMAR797, or pMAR799, expressing GFP, WT-PRIM1-GFP-WT, or C301R-PRIM1-GFP, respectively) using the Invitrogen Neon kit (MPK10096) according to the manufacturer's instructions ( $2.5 \mu$ of plasmid DNA for $1 \times 10^{6}$ cells, 20 -msec pulse width). Twenty-four hours after electroporation, cells were pulsed with CldU and IdU (as above), trypsinized, and sorted on a BD FACSAria to select GFP-positive, successfully transfected cells. Cells were collected in AmnioMAX C-100, seeded on coverslips in 24-well plates for $1.5 \mathrm{~h}$, and subsequently fixed in $4 \%$ PFA. Immunofluorescence for CldU and IdU, as outlined below, was per- formed using rat anti-BrdU (Abcam ab6326) and mouse antiBrdU (BD 347580).

Immunofluorescence

Fibroblasts were grown on coverslips for $24 \mathrm{~h}$, fixed with $4 \%$ PFA, washed, and blocked for $1 \mathrm{~h}$ in $10 \%$ goat serum/PBS/0.1\% Triton. Independent coverslips were incubated with p21 (1:200; Calbiochem OP64), cleaved caspase 3 (1:1000; Cell Signaling 9661), $\gamma \mathrm{H} 2 \mathrm{AX}$ (1:1000; Millipore 05-636), or RPA2 (1:200; Calbiochem NA19L) antibodies. After overnight incubation in primary antibodies, signals were detected using fluorescently conjugated antibodies and costained with DAPI. For all antibodies except cleaved caspase 3 and p21, cells were pre-extracted for $5 \mathrm{~min}$ on ice with ice-cold buffer (25 mM HEPES at $\mathrm{pH} 7.4,50 \mathrm{mM} \mathrm{NaCl}, 1 \mathrm{mM}$ EDTA, $3 \mathrm{mM} \mathrm{MgCl}_{2}, 300 \mathrm{mM}$ sucrose, $0.5 \%$ Triton X-100) before fixation to remove soluble proteins and detection of chromatinbound fractions. For $\gamma-\mathrm{H} 2 \mathrm{AX}$ staining, cells were pulsed with 20 $\mu \mathrm{M}$ EdU (Sigma 900584) for $1 \mathrm{~h}$ before fixation. EdU was detected subsequent to immunofluorescence using the click reaction and azide-Alexa fluor 488 (Thermo Fisher A10266).

\section{DNA combing}

Primary fibroblast cells exponentially growing in AmnioMAX C100 (Thermo Fisher Scientific 17001074) medium under hypoxic conditions were pulsed with $25 \mu \mathrm{M}$ CldU (Sigma C6891) for 20 min, washed with prewarmed PBS, and then pulsed with 125 $\mu \mathrm{M}$ IdU (Sigma I7125) for $20 \mathrm{~min}$. After trypsinization, $5 \times 10^{5}$ cells were used to cast three to four agarose (Bio-Rad 1613111) plugs per condition and processed for DNA combing according to a previously described protocol (Gallo et al. 2016), omitting the SCE buffer plug digestion steps. IdU and CldU were detected using mouse anti-BrdU (BD 347580) and rat anti-BrdU (Abcam ab6326), respectively. DNA was detected using anti-ssDNA antibody (Millipore MAB 3034). Images were acquired on a wide-field microscope (Zeiss Axiophot) with a $63 \times$ or $40 \times$ lens. The $2.33-\mathrm{kb} /$ $\mu \mathrm{m}$ elongation rate (micron to kilobase conversion) was obtained from bacteriophage $\lambda$ DNA combing and measurement, as described previously (Gallo et al. 2016). Measurements and analysis were performed using ImageJ. DNA fork speed was obtained dividing the length of the IdU track-adjacent CldU tracks (ongoing forks) by the IdU incubation time $(20 \mathrm{~min})$ and is expressed in kilobases per minute. Fork asymmetry is presented as left IdU versus right IdU ratios. Interorigin distances (IODs) correspond to the space (in kilobases) between the center points of adjacent bidirectional replication origins.

\section{Data access}

WGS data from families 1-3 are available on request from the relevant Data Access Committee from the European GenomePhenome Archive (EGA) under accession number EGAS0000 1004703.

\section{The Scottish Genomes Partnership}

Members of the Scottish Genome Partnership include Timothy J. Aitman, ${ }^{9}$ Andrew V. Biankin, ${ }^{10}$ Susanna L. Cooke, ${ }^{10}$ Wendy Inglis Humphrey, ${ }^{9}$ Sancha Martin, ${ }^{10}$ Lynne Mennie, ${ }^{11}$

${ }^{9}$ Centre for Genomic and Experimental Medicine, MRC Institute of Genetics and Molecular Medicine, the University of Edinburgh, Edinburgh EH4 2XU, United Kingdom

${ }^{10}$ Wolfson Wohl Cancer Research Centre, Institute of Cancer Sciences, University of Glasgow, Glasgow G61 1QH, United Kingdom

${ }^{11}$ University of Aberdeen, Aberdeen AB24 3FX, United Kingdom 
Alison Meynert, ${ }^{12}$ Zosia Miedzybrodzka, ${ }^{13}$ Fiona Murphy, ${ }_{1}^{14}$ Craig Nourse, ${ }^{10}$ Javier Santoyo-Lopez, ${ }^{15}$ Colin A. Semple, ${ }^{12}$ and Nicola Williams ${ }^{16}$

\section{Acknowledgments}

We thank the families and clinicians for their involvement and participation; John Wyrick, Jean Beggs, Thomas Cooper, Ramanujan Hegde, and Aziz El Hage for reagents; the Institute of Genetics and Molecular Medicine (IGMM) Advanced Imaging Resource for advice; E. Freyer for assistance with FACS analysis; the IGMM core sequencing service; Ailith Ewing for helpful discussion; Margaret MacDonald for assistance with clinical case characterization; and Edinburgh Genomics (Clinical Division) for WGS sequencing. This work was supported by the European Union's Horizon 2020 research and innovation program ERC Advanced Grant (grant agreement 788093), by a UK Medical Research Council (MRC) Human Genetics Unit core grant (MRC, U127580972), and the Scottish Genomes Partnership. L.T.-O. is also supported by an Embo ALTF 739-2019. J.A.M. is supported by an MRC Career Development Award (MR/M02122X/1) and is a Lister Institute Research Prize Fellow. The Scottish Genomes Partnership is funded by the Chief Scientist Office of the Scottish Government Health Directorates (SGP/1) and The Medical Research Council Whole-Genome Sequencing for Health and Wealth Initiative. The DDD Study presents independent research commissioned by the Health Innovation Challenge Fund (grant no. HICF-1009-003). This study makes use of DECIPHER (http ://decipher.sanger.ac.uk), which is funded by Wellcome. See Nature PMID: 25533962 or http://www.ddduk.org/access.html for full acknowledgement.

Author contributions: A.P.J. and D.A.P. designed the study. D.A.P. analyzed genetic data. L.T.-O., P.C., M.A.M.R., O.M., C.U., and A.L. performed laboratory experiments. L.T.-O., P.C., M.A.M.R., D.A.P., and A.P.J. analyzed experimental data. J.A.M. and D.A.P. analyzed protein structure data. R.K., G.M., A.N., B.O., B.K.-P., A.J.Q., M.R., J.R., K.S., and A.P.J. recruited and evaluated study participants. D.A.P., A.P.J., L.T.-O., and M.A.M.R. wrote the manuscript.

\section{References}

Bellelli R, Borel V, Logan C, Svendsen J, Cox DE, Nye E, Metcalfe K, O'Connell SM, Stamp G, Flynn HR, et al. 2018. Pole instability drives replication stress, abnormal development, and tumorigenesis. Mol Cell 70: 707-721.e7. doi:10.1016/j.molcel .2018.04.008

Bicknell LS, Bongers EMHF, Leitch A, Brown S, Schoots J, Harley ME, Aftimos S, Al-Aama JY, Bober M, Brown PAJ, et al. 2011a. Mutations in the pre-replication complex cause Meier-Gorlin syndrome. Nat Genet 43: 356-359. doi:10.1038/ng.775

Bicknell LS, Walker S, Klingseisen A, Stiff T, Leitch A, Kerzendorfer C, Martin C-A, Yeyati P, Al Sanna N, Bober M, et al. 2011b.

\footnotetext{
${ }^{12}$ MRC Human Genetics Unit, MRC Institute of Genetics and Molecular Medicine, the University of Edinburgh, Edinburgh EH4 2XU, United Kingdom

${ }^{13}$ Department of Medical Genetics, Ashgrove House, NHS Grampian, Aberdeen AB25 2ZA, United Kingdom

${ }^{14}$ National Services Division, NHS National Services Scotland, Edinburgh EH12 9EB, United Kingdom

${ }^{15}$ Edinburgh Genomics Clinical Division, the Roslin Institute, University of Edinburgh, Edinburgh EH25 9RG, United Kingdom

${ }^{16}$ West of Scotland Genetic Services, Queen Elizabeth University Hospital, Glasgow G51 4TF, United Kingdom
}

Mutations in ORC1, encoding the largest subunit of the origin recognition complex, cause microcephalic primordial dwarfism resembling Meier-Gorlin syndrome. Nat Genet 43: 350355. doi:10.1038/ng.776

Blake JA, Bult CJ, Kadin JA, Richardson JE, Eppig JT. 2011. The Mouse Genome Database (MGD): premier model organism resource for mammalian genomics and genetics. Nucleic Acids Res 39: D842-D848. doi:10.1093/nar/gkq1008

Burrage LC, Charng WL, Eldomery MK, Willer JR, Davis EE, Lugtenberg D, Zhu W, Leduc MS, Akdemir ZC, Azamian M, et al. 2015. De novo GMNN mutations cause autosomal-dominant primordial dwarfism associated with Meier-Gorlin syndrome. Am J Hum Genet 97: 904-913. doi:10.1016/j.ajhg.2015.11.006

Chen W-H, Lu G, Chen X, Zhao X-M, Bork P. 2017. OGEE v2: an update of the online gene essentiality database with special focus on differentially essential genes in human cancer cell lines. Nucleic Acids Res 45: D940-D944. doi:10.1093/nar/ gkw1013

Conde CD, Petronczki ÖY, Baris S, Willmann KL, Girardi E, Salzer E, Weitzer S, Ardy RC, Krolo A, Ijspeert H, et al. 2019. Polymerase $\delta$ deficiency causes syndromic immunodeficiency with replicative stress. I Clin Invest 129: 4194-4206. doi:10 $.1172 /$ JCI128903

Cottineau J, Kottemann MC, Lach FP, Kang YH, Vély F, Deenick EK, Lazarov T, Gineau L, Wang Y, Farina A, et al. 2017. Inherited GINS1 deficiency underlies growth retardation along with neutropenia and NK cell deficiency. I Clin Invest 127: 1991-2006. doi:10.1172/JCI90727

Crooks GE, Hon G, Chandonia JM, Brenner SE. 2004. Weblogo: a sequence logo generator. Genome Res 14: 1188-1190. doi:10 $.1101 /$ gr.849004

Cunningham F, Amode MR, Barrell D, Beal K, Billis K, Brent S, Carvalho-Silva D, Clapham P, Coates G, Fitzgerald S, et al. 2015. Ensembl 2015. Nucleic Acids Res 43: D662-D669. doi:10.1093/nar/gku1010

Czechowska A, Błasiak J. 2005. Eukaryotic DNA polymerases. Postepy Biochem 51: 130-139.

Faust GG, Hall IM. 2014. SAMBLASTER: fast duplicate marking and structural variant read extraction. Bioinformatics 30: 2503-2505. doi:10.1093/bioinformatics/btu314

Fenwick AL, Kliszczak M, Cooper F, Murray J, Sanchez-Pulido L, Twigg SRF, Goriely A, McGowan SI, Miller KA, Taylor IB, et al. 2016. Mutations in CDC45, encoding an essential component of the pre-initiation complex, cause Meier-Gorlin syndrome and craniosynostosis. Am J Hum Genet 99: 125-138. doi:10.1016/j.ajhg.2016.05.019

Frick DN, Richardson CC. 2001. DNA primases. Annu Rev Biochem 70: 39-80. doi:10.1146/annurev.biochem.70.1.39

Frugoni F, Dobbs K, Felgentreff K, Aldhekri H, Al Saud BK, Arnaout R, Ali AA, Abhyankar A, Alroqi F, Giliani S, et al. 2016. A novel mutation in the POLE2 gene causing combined immunodeficiency. I Allergy Clin Immunol 137: 635-638.e1. doi:10 $.1016 /$ j.jaci.2015.06.049

Gallo D, Wang G, Yip CM, Brown GW. 2016. Analysis of replicating yeast chromosomes by DNA combing. Cold Spring Harb Protoc 2016: 138-149.

Gineau L, Cognet C, Kara N, Lach FP, Dunne J, Veturi U, Picard C, Trouillet C, Eidenschenk C, Aoufouchi S, et al. 2012. Partial MCM4 deficiency in patients with growth retardation, adrenal insufficiency, and natural killer cell deficiency. J Clin Invest 122: 821-832. doi:10.1172/JCI61014

Guernsey DL, Matsuoka M, Jiang H, Evans S, MacGillivray C, Nightingale M, Perry S, Ferguson M, Leblanc M, Paquette J, et al. 2011. Mutations in origin recognition complex gene 
ORC4 cause Meier-Gorlin syndrome. Nat Genet 43: 360-364. doi:10.1038/ng. 777

Jaganathan K, Kyriazopoulou Panagiotopoulou S, McRae JF, Darbandi SF, Knowles D, Li YI, Kosmicki JA, Arbelaez J, Cui W, Schwartz GB, et al. 2019. Predicting splicing from primary sequence with deep learning. Cell 176: 535-548.e24. doi:10 .1016/j.cell.2018.12.015

Juszkiewicz S, Hegde RS. 2017. Initiation of quality control during poly(A) translation requires site-specific ribosome ubiquitination. Mol Cell 65: 743-750.e4. doi:10.1016/j.molcel.2016 .11 .039

Karczewski KJ, Francioli LC, Tiao G, Cummings BB, Alföldi J, Wang Q, Collins RL, Laricchia KM, Ganna A, Birnbaum DP, et al. 2020. The mutational constraint spectrum quantified from variation in 141,456 humans. Nature 581: 434-443. doi:10.1038/s41586-020-2308-7

Kirk BW, Kuchta RD. 1999. Arg304 of human DNA primase is a key contributor to catalysis and NTP binding: primase and the family X polymerases share significant sequence homology. Biochemistry 38: 7727-7736. doi:10.1021/bi990247c

Klingseisen A, Jackson AP. 2011. Mechanisms and pathways of growth failure in primordial dwarfism. Genes Dev 25: 20112024. doi:10.1101/gad.169037

Lander ES, Botstein D. 1987. Homozygosity mapping: a way to map human recessive traits with the DNA of inbred children. Science 236: 1567-1570. doi:10.1126/science.2884728

Laughery MF, Hunter T, Brown A, Hoopes J, Ostbye T, Shumaker T, Wyrick JJ. 2015. New vectors for simple and streamlined CRISPR-Cas9 genome editing in Saccharomyces cerevisiae. Yeast 32: 711-720. doi:10.1002/yea.3098

Li H. 2013. Aligning sequence reads, clone sequences and assembly contigs with BWA-MEM. arXiv 1303.3997

Logan CV, Murray JE, Parry DA, Robertson A, Bellelli R, Tarnauskaitè Ž, Challis R, Cleal L, Borel V, Fluteau A, et al. 2018. DNA polymerase $\varepsilon$ deficiency causes IMAGe syndrome with variable immunodeficiency. Am I Hum Genet 103: 10381044. doi:10.1016/j.ajhg.2018.10.024

Martynoga B, Morrison H, Price DI, Mason JO. 2005. Foxg1 is required for specification of ventral telencephalon and regionspecific regulation of dorsal telencephalic precursor proliferation and apoptosis. Dev Biol 283: 113-127. doi:10.1016/j.ydbio .2005 .04 .005

McKenna A, Hanna M, Banks E, Sivachenko A, Cibulskis K, Kernytsky A, Garimella K, Altshuler D, Gabriel S, Daly M, et al. 2010. The genome analysis toolkit: a MapReduce framework for analyzing next-generation DNA sequencing data. Genome Res 20: 1297-1303. doi:10.1101/gr.107524.110

McLaren W, Gil L, Hunt SE, Riat HS, Ritchie GRS, Thormann A, Flicek P, Cunningham F. 2016. The ensembl variant effect predictor. Genome Biol 17: 122. doi:10.1186/s13059-016-0974-4

Niedenthal RK, Riles L, Johnston M, Hegemann JH. 1996. Green fluorescent protein as a marker for gene expression and subcellular localization in budding yeast. Yeast 12: 773-786. doi:10.1002/(SICI)1097-0061(19960630)12:8<773::AIDYEA972>3.0.CO;2-L

Pachlopnik Schmid J, Lemoine R, Nehme N, Cormier-Daire V, Revy P, Debeurme F, Debré M, Nitschke P, Bole-Feysot C, Legeai-Mallet L, et al. 2012. Polymerase $\varepsilon 1$ mutation in a human syndrome with facial dysmorphism, immunodeficiency, livedo, and short stature ('FILS syndrome'). I Exp Med 209: 2323-2330. doi:10.1084/jem.20121303

Reese MG, Eeckman FH, Kulp D, Haussler D. 1997. Improved splice site detection in genie. I Comput Biol 4: 311-323. Mary Ann Liebert Inc. doi:10.1089/cmb.1997.4.311

Reynolds JJ, Bicknell LS, Carroll P, Higgs MR, Shaheen R, Murray JE, Papadopoulos DK, Leitch A, Murina O, Tarnauskaitė Ž, et al. 2017. Mutations in DONSON disrupt replication fork stability and cause microcephalic dwarfism. Nat Genet 49: 537-549. doi:10.1038/ng.3790

Rowen L, Kornberg A. 1978. Primase, the dnaG protein of Escherichia coli. An enzyme which starts DNA chains. J Biol Chem 253: 758-764.

Schymkowitz J, Borg J, Stricher F, Nys R, Rousseau F, Serrano L. 2005. The FoldX web server: an online force field. Nucleic Acids Res 33: W382-W388. doi:10.1093/nar/gki387

Singh G, Cooper TA. 2006. Minigene reporter for identification and analysis of cis elements and trans factors affecting premRNA splicing. BioTechniques 41: 177-181. doi:10.2144/ 000112208

Starokadomskyy P, Gemelli T, Rios JJ, Xing C, Wang RC, Li H, Pokatayev V, Dozmorov I, Khan S, Miyata N, et al. 2016. DNA polymerase- $\alpha$ regulates the activation of type I interferons through cytosolic RNA:DNA synthesis. Nat Immunol 17: 495-504. doi:10.1038/ni.3409

Tarnauskaite Ž, Bicknell LS, Marsh JA, Murray JE, Parry DA, Logan CV, Bober MB, Silva DC, Duker AL, Sillence D, et al. 2019. Biallelic variants in DNA2 cause microcephalic primordial dwarfism. Hum Mutat 40: humu.23776. doi:10.1002/humu .23776

Thiffault I, Saunders C, Jenkins J, Raje N, Canty K, Sharma M, Grote L, Welsh HI, Farrow E, Twist G, et al. 2015. A patient with polymerase E1 deficiency (POLE1): clinical features and overlap with DNA breakage/instability syndromes. BMC Med Genet 16: 31. doi:10.1186/s12881-015-0177-y

Van der Auwera GA, Carneiro MO, Hartl C, Poplin R, del Angel G, Levy-Moonshine A, Jordan T, Shakir K, Roazen D, Thibault J, et al. 2013. From FastQ data to high-confidence variant calls: the genome analysis toolkit best practices pipeline. Curr Protoc Bioinformatics 43: 11.10.1-11.10.33. doi:10.1002/ 0471250953.bil110s43

Van Esch H, Colnaghi R, Freson K, Starokadomskyy P, Zankl A, Backx L, Abramowicz I, Outwin E, Rohena L, Faulkner C, et al. 2019. Defective DNA polymerase a-primase leads to $\mathrm{X}$-linked intellectual disability associated with severe growth retardation, microcephaly, and hypogonadism. Am J Hum Genet 104: 957-967. doi:10.1016/j.ajhg.2019.03.006

Vetro A, Savasta S, Russo Raucci A, Cerqua C, Sartori G, Limongelli I, Forlino A, Maruelli S, Perucca P, Vergani D, et al. 2017. MCM5: a new actor in the link between DNA replication and Meier-Gorlin syndrome. Eur J Hum Genet 25: 646-650. doi:10 .1038/ejhg.2017.5

Weedon MN, Ellard S, Prindle MJ, Caswell R, Allen HL, Oram R, Godbole K, Yajnik CS, Sbraccia P, Novelli G, et al. 2013. An in-frame deletion at the polymerase active site of POLD1 causes a multisystem disorder with lipodystrophy. Nat Genet 45: 947-950. doi:10.1038/ng.2670

Yeo G, Burge CB. 2004. Maximum entropy modeling of short sequence motifs with applications to RNA splicing signals. I Comput Biol 11: 377-394. doi:10.1089/1066527041410418 


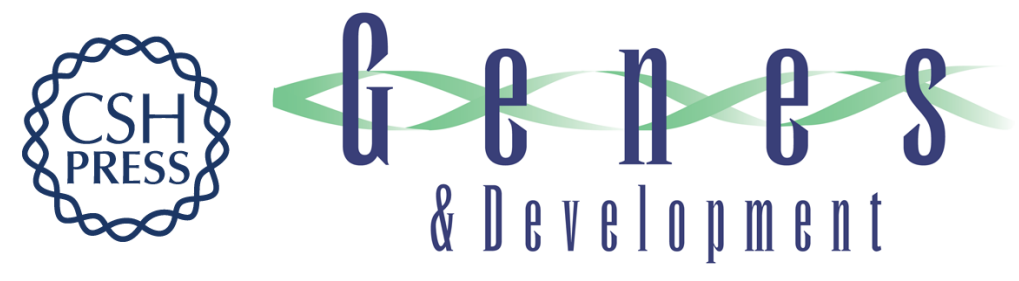

\section{PRIM1 deficiency causes a distinctive primordial dwarfism syndrome}

David A. Parry, Lukas Tamayo-Orrego, Paula Carroll, et al.

Genes Dev. 2020, 34: originally published online October 15, 2020

Access the most recent version at doi:10.1101/gad.340190.120

\section{Supplemental http://genesdev.cshlp.org/content/suppl/2020/10/14/gad.340190.120.DC1 \\ Material \\ References This article cites 44 articles, 6 of which can be accessed free at: http://genesdev.cshlp.org/content/34/21-22/1520.full.html\#ref-list-1 \\ Creative This article, published in Genes \& Development, is available under a Creative Commons Commons License (Attribution 4.0 International), as described at License http://creativecommons.org/licenses/by/4.0/. \\ Email Alerting Receive free email alerts when new articles cite this article - sign up in the box at the top Service right corner of the article or click here.}

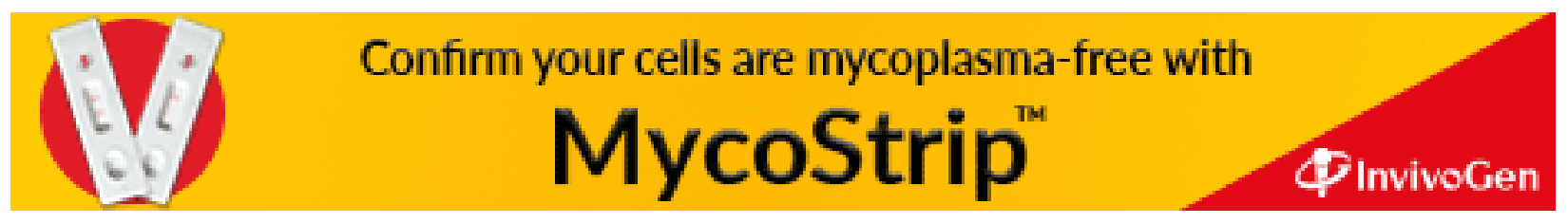

